\title{
Turismo, gastronomía y producción agraria en la provincia de Jujuy (Argentina): actores, dinámicas y transformaciones asociadas a la valorización de productos tradicionales*
}

\author{
Tourism, gastronomy and agrarian production in Jujuy (Argentina): actors, dynamics and \\ transformations associated to traditional agrarian food
}

\section{Claudia Alejandra Troncoso (iD, CONICET-Universidad de Buenos Aires, Argentina claudia.a.troncoso@gmail.com}

\section{Mariana Beatriz Arzeno (D, CONICET-Universidad de Buenos Aires, Argentina mariana.arzeno@conicet.gov.ar}

\section{RESUMEN}

El objetivo de este trabajo es poner en discusión la relación entre turismo, producción agraria, valorización de alimentos y desarrollo que se teje en los destinos turísticos. Para ello recuperamos perspectivas teóricas, en particular de la Geografía, que nos permiten abordar tal relación en su complejidad, teniendo en cuenta las redes de actores que se conforman y las relaciones que establecen sus participantes. Para poner en discusión estas cuestiones, nos remitimos a los cambios asociados a la valorización turística de alimentos y preparaciones culinarias tradicionales de la Quebrada de Humahuaca y Puna en el norte argentino. Recurrimos al diseño de una estrategia metodológica apoyada en entrevistas con los actores participantes (productores, empresarios turísticos, funcionarios públicos) complementada con información obtenida de la observación sistemática en los espacios de producción y consumo en el área de estudio. Los resultados de la investigación muestran que la valorización turística de alimentos (y de los lugares con que se asocian) es producto de un proceso social en el que ciertos actores, relaciones e intercambios tuvieron y tienen un rol central. También se señala que se trata de un proceso pensado por (y en cierta forma para) el consumo de sectores sociales específicos. En este sentido, se cuestionan las aspiraciones de generar un "desarrollo" automático para sectores mayoritarios de la población local a partir de la promoción y expansión del turismo (y específicamente del turismo gastronómico).

Palabras clave: turismo, gastronomía, lugar, Jujuy, Argentina

\footnotetext{
* Este trabajo es una versión revisada y ampliada de la ponencia presentada en el Congreso Internacional de Investigación "Turismo y Buen Vivir" (Universidad Externado de Colombia, octubre de 2017).
} 


\section{ABSTRACT}

The aim of this article is to discuss the links between tourism, agrarian production, food valorization and development within tourist destinations. We have based this discussion on theoretical perspectives (particularly from Geography) so as to understand the complexity of these connections, taking into account the network of agents of which they are formed and the relationships established between their participants. To discuss these ideas, we analyze the tourist valorization of typical Andean foods and the cuisine of Quebrada de Humahuaca and Puna (Northern Argentina). We have conducted qualitative interviews with farmers, tourism entrepreneurs, and public officials. Systematic in situ observation in production and consumption spaces has also been carried out. The research shows that the tourist valorization of foods (and places associated to their production) is result of a social process defined by certain social relations that have configured local society. The study also reveals that this tourist valorization process has been conceived by (and for) particular social actors considering their consumption interests. Therefore, the paper contests the aspiration to achieve the automatic development for local societies through the promotion of tourism expansion (specifically, culinary tourism).

Keywords: tourism, gastronomy, place, Jujuy, Argentina

\section{INTRODUCCIÓN}

Desde diferentes ámbitos relacionados con el turismo y la producción agraria se expresan con frecuencia propuestas que buscan poner a disposición de los turistas una producción (y una gastronomía asociada) que no solo ofrece la posibilidad de conocer aspectos específicos de la cultura local sino que además brindaría la oportunidad para encarar procesos de desarrollo. La Organización Mundial del Turismo (OMT), por ejemplo, expresa que: "el turismo gastronómico ofrece un enorme potencial para estimular las economías locales, regionales y nacionales y mejorar la sustentabilidad y la inclusión", lo cual requiere "asociaciones público-privadas para crear una estrategia de promoción exitosa" (OMT, 2017: 10 y 12). De ahí que la cuestión de la articulación de actores (empresarios funcionarios, organizaciones, población local) se vuelve clave y es objeto de reflexiones y de propuestas.

En el caso de la Argentina esta cuestión viene cobrando relevancia. Las "rutas alimentarias" o simplemente la producción de cultivos tradicionales son las primeras iniciativas que buscan articular alimentos/gastronomía con turismo. Ellas han tenido diversos orígenes y en la actualidad reciben el respaldo de entidades estatales como la Secretaría de Agroindustria (Alimentos Argentinos, 2018). Otras iniciativas incluyen la creación a nivel nacional del Plan CocinAR (2016) en el ámbito de la Secretaría de Turismo, orientado a la valorización de la comida como atractivo turístico y al turismo gastronómico como impulsor del desarrollo local. Desde el INTA (Instituto Nacional de Tecnología Agropecuaria), por su parte, se creó el programa "Del territorio al plato", que valoriza y promueve los alimentos y la cocina de distintos lugares del país, buscando favorecer tanto la producción como el turismo en esos lugares.

Esta confianza expresada en los alimentos y la gastronomía como atractivos turísticos proliferan en un contexto de cambios en la forma de producir y consumir alimentos que han tenido lugar en las últimas décadas. Estos cambios están marcados principalmente por 
un interés creciente por el consumo de nuevos productos naturales, orgánicos, saludables y también aquellos que remiten a culturas y lugares específicos. Los denominados "productos de nicho", de alto valor o specialties cobran una importancia cada vez mayor en el mercado de alimentos, en particular porque responden a esas nuevas demandas de consumo de sectores de ingresos medios y altos interesados en su calidad, su origen geográfico y cultural, así como las condiciones (ambientales, laborales) en las que se producen.

El interés en el consumo de alimentos con estas características se hace presente en el turismo, donde se pone en juego la búsqueda de la autenticidad y asociado a ella el interés del turismo por preservar lo que asume como distintivo y tradicional de cada lugar (Mowforth y Munt, 1998). En ese marco, la gastronomía se ha transformado en un atractivo de primer nivel para varios destinos. $Y$ esto ha formado parte de los debates y propuestas en torno al desarrollo local, territorial, sustentable, expresados en torno a fórmulas que promueven maneras de llevar adelante el turismo que asistan e impulsen mejoras en las condiciones de vida de las sociedades residentes en los destinos turísticos.

También ha constituido un punto central en la producción académica respecto de estas cuestiones. La literatura abocada a dar cuenta de la relación entre el turismo y la producción de alimentos de origen agrario (nombradas como turismo gastronómico, culinario, agroalimentario, entre otras variantes) es amplia y abarca diversas temáticas, así como también perspectivas de análisis y múltiples propósitos. Esta producción incluye compilaciones que ofrecen un panorama acerca de la variedad de aspectos en que se desdobla el tema (véanse, por ejemplo: Hall, et al., 2003; Torres y Momsen, 2011; Sidali, et al., 2011; Norrild, 2016; Dixit, 2019). El interés también ha llevado a la organización de dossiers en revistas científicas como el número de la revista Pasos. Turismo y patrimonio cultural sobre "Turismo gastronómico y enológico" de 2008; el publicado en el Journal of Heritage Tourism ("Heritage cuisines") en 2013 y el organizado por la revista Téoros en 2016 ("Tourisme et gastronomie"). La profusa literatura dedicada al tema se ha abocado a conocer en detalle aspectos como: los procesos por los cuales se obtienen y consumen productos de origen agrario con denominaciones oficiales (Millán Vázquez de la Torre, et al., 2014; Amaya-Corchuelo et al., 2019); las rutas gastronómicas o alimentarias como formas especifica de organizar visitas y experiencias turísticas (Prat Forga y Cànoves Valiente, 2012; López Guzmán y Jesús, 2011); las motivaciones de los turistas que consumen experiencias vinculadas con el turismo gastronómico (Bessière et al., 2016; Cohen y Avieli, 2004; Hernández Mogollón et al., 2015; Goolap et al., 2019); los vínculos entre interés turístico por la gastronomía y procesos de designaciones patrimoniales internacionales (Mata, 2012; Csergo, 2016), entre otros.

El interés por una combinación fructífera entre turismo y producción agraria está presente en buena parte de la literatura que, en ocasiones, incluye recomendaciones para lograrlo. En el presente trabajo el foco está puesto en la incidencia que la demanda (turística) de productos agrarios tiene en las formas que adquiere la producción de estos productos. Asimismo, indaga algunos aspectos de esta relación que pueden ayudar a comprender los variados resultados que adquiere el vínculo entre turismo y producción agraria. Como punto de partida se sostiene que esto es posible con un análisis que se adentre en la comprensión de las dinámicas específicas de las sociedades de los destinos turísticos para conocer quiénes, cómo, con quiénes logran obtener mejoras en su producción, controlar circuitos de 
comercialización y acceder a recursos específicos (tierra, insumos, herramientas, etc.). En este trabajo, se retoman variados aportes para analizar la compleja relación entre turismo, producción agraria, valorización de alimentos y desarrollo que se tejen en los lugares turísticos con el fin de conocer cuáles son las transformaciones específicas que los definen.

Para poner en discusión estas cuestiones, aquí se abordan los cambios asociados a la valorización turística de alimentos y preparaciones culinarias tradicionales en un ámbito geográfico en particular: la Quebrada de Humahuaca y Puna en el norte argentino (provincia de Jujuy) que vienen atravesando procesos de cambio asociados a la demanda de productos tradicionales, en particular de la mano del desarrollo del turismo en esta provincia (Arzeno, 2008 y Troncoso, 2012). La Quebrada de Humahuaca, específicamente, es el lugar donde se concentra la oferta de servicios turísticos. Constituye un destino tradicional del turismo argentino que, desde que fue declarado Patrimonio de la Humanidad por la UNESCO en 2003, ha experimentado un importante aumento en el número de visitas y de servicios turísticos ofrecidos en el lugar. En particular han proliferado locales gastronómicos en las localidades de Tilcara, Purmamarca y Humahuaca orientados a ofrecer productos y preparaciones identificadas como tradicionales o típicas de la Quebrada o del mundo andino en general.

Asimismo, el interés por estos productos ha sido retomado por organizaciones de productores, que intentaron recuperar cultivos, técnicas y conocimientos con la expectativa de satisfacer la demanda.

Este trabajo, entonces, busca indagar cómo se ha transformado el panorama productivo y turístico de estas áreas en vinculación con la recuperación de alimentos tradicionales: quiénes son los actores que participan, a través de qué producciones ( $y$ cómo ellas han cambiado en función de esta nueva demanda), qué relación existe entre ellos y los turistas interesados en esos productos, cómo se vinculan con diferentes agentes estatales orientados a promocionar esta producción y su consumo, etc. El abordaje de estas cuestiones parte de una perspectiva teórica que recupera algunas discusiones generadas en la Geografía en torno al concepto de lugar, para proponer el análisis en la complejidad de las tramas sociales que dan forma a los procesos que definen a los lugares. Una forma de aproximación a esta complejidad es observando las distintas redes de actores vinculados a la producción y el consumo en las que se ponen en juego diferencias culturales, de saberes e incluso de clase, étnicas y de género (Goodman, 2010). De la mano de estas perspectivas, se procura, entonces, dialogar con los abordajes vigentes acerca de la relación entre turismo, producción agraria y desarrollo.

\section{MARCO CONCEPTUAL}

\subsection{Producción agraria, sociedades locales y lugar}

El contexto de cambios en la producción y el consumo de alimentos llevan a interrogarse acerca de los actores que participan de estos procesos y que transforman lugares específicos orientados por estas ideas y tendencias.

En este trabajo, lejos de asumir las ideas de homogeneidad, armonía, objetivos comunes y cooperación que suele atribuirse a las sociedades locales (especialmente en ámbitos rurales, de pequeños productores o grupos indígenas) (Barros, 2000) se opta por abordar a las 
sociedades en tanto compuestas por diferentes actores con distintos intereses, con una desigual capacidad de acción, que a su vez establecen relaciones y vinculaciones variadas entre sí.

Las discusiones sobre este tema han estado casi ausentes en los estudios turísticos (Salazar, 2012) y la aceptación como supuesto de la ausencia de desigualdades y conflicto en este tipo de formas de organización social ha llevado directamente a no indagar en estas cuestiones.

Las diferencias sociales, la existencia o el surgimiento de elites locales y las posibilidades diferenciales de instalar proyectos y llevar adelante acciones son elementos que indefectiblemente interactúan con todo tipo de iniciativas para generar desarrollo (a partir del turismo o de cualquier otra actividad). Esto implica, entre otras cosas, que estas diferencias pueden dar lugar a una distribución desigual en los beneficios que se busca generar mediante las propuestas de desarrollo (Salazar, 2006).

Reconocer estas cuestiones es indispensable no solo para comenzar a indagar en las complejidades de las sociedades locales vinculadas a un destino turístico sino también para dejar de lado preguntas (y respuestas) acerca de si el turismo es positivo o negativo para estas sociedades, si destruye o habilita posibilidades. En cada situación, el turismo interactúa con una sociedad con características propias y esta interacción genera resultados variados según los casos. Y esto es resultado de una combinación particular de ciertas trayectorias y dinámica social en su encuentro con formas específicas que toma el turismo en ese lugar.

En pos de abordar la complejidad de la trama de actores que tienen incidencia en las transformaciones de lugares vinculados a estos procesos de valorización de alimentos recurrimos a algunos desarrollos conceptuales de la Geografía, en particular las discusiones planteadas por Doreen Massey $(2007 ; 2012)$ relativas a cómo entender el lugar, sus vínculos con lo global, la identidad y la comunidad.

Massey entiende el lugar como un nodo abierto de relaciones, de flujos, influencias e intercambios; un resultado en permanente transformación de una constelación determinada de relaciones sociales ( $y$ de poder) que se encuentran y entretejen en un sitio particular. Desde esta perspectiva, los lugares no se cierran en sí mismos, ni se contraponen con "lo global", sino que podemos imaginarlos "como momentos articulados en redes de relaciones e interpretaciones sociales en los que una gran proporción de estas relaciones, experiencias e interpretaciones están construidas a una escala mucho mayor que la que define en aquel momento el sitio mismo" (Massey, 2012: 126). Por lo tanto, lo que confiere especificidad a ese lugar no es una larga historia internalizada sino el hecho de estar constituido por esa constelación de relaciones particular en ese momento.

Asimismo, de acuerdo con Massey (2012) el sentido de lugar y la identidad que se construye desde/con el lugar no es igual para todos los sectores que lo habitan. Justamente la posición diferencial de las personas tanto dentro del lugar como en las relaciones que establecen con contextos más amplios, es lo que impide sostener la idea de "comunidad" asociada a la coherencia, cohesión y sentidos de lugar o identidades únicas.

Una forma de identificar esas relaciones es a través del análisis de las distintas redes de producción-consumo de alimentos locales, de calidad o alternativos. En relación con esto, 
Goodman (2010) Ilama la atención sobre la necesidad de traer el análisis social crítico para examinar "la distribución de ganancias derivadas de estas nuevas actividades económicas entre los actores locales y extralocales, y localmente, a lo largo de las líneas de clase, género, raza y etnia" (p. 189-190). Entre otras cuestiones, y en relación con las relaciones sociales de consumo, el autor destaca que

los precios marcadamente más altos, los compromisos de espacio-tiempo necesarios para adquirir y preparar estos alimentos alternativos y locales, y los conocimientos alimentarios involucrados, sugieren fuertemente que se requieren niveles significativos de capital económico y cultural para obtener acceso a estos sistemas de aprovisionamiento (p. 197)

y podríamos agregar, para participar de estas redes desde el lado de la oferta de productos.

Esta perspectiva de las redes de producción-consumo alternativos nos lleva además a poner la mirada en: (i) quiénes son los actores que activan (y participan de) estos procesos en términos de sus trayectorias y capitales (económico, social, cultural); (ii) qué vínculos se establecen entre productores y consumidores, tanto en el nivel local como en otros ámbitos; y por último (iii) cuáles son los espacios de consumo en relación a la producción y valorización de alimentos y cómo son acondicionados en torno a la estética gastronómica actual.

Estos aportes conceptuales organizan el tratamiento y exposición que sigue. En primer lugar, se analizan las características que asumen la revalorización de la producción agraria tradicional de la Quebrada y Puna. Luego, se aborda cómo se vincula esa producción con la demanda creciente desde el consumo gastronómico y turístico. Por último, se pone en discusión cómo se intenta promover y articular desde el ámbito público la producción-consumo de alimentos tradicionales en el lugar. Todo esto es analizado poniendo el foco en los actores centrales en esos procesos.

\section{METODOLOGÍA}

Para realizar este trabajo se ha recurrido al diseño de una estrategia metodológica apoyada fundamentalmente en entrevistas semiestructuradas con los actores participantes de los procesos de producción, transformación y distribución de los productos agrarios andinos. La selección de estos entrevistados es intencionada en la medida en que se buscaba conocer a los actores involucrados directamente con los procesos en análisis ${ }^{1}$. Estas entrevistas incluyen miembros de asociaciones de productores locales dedicados a la producción agraria y orientados en el último tiempo a la producción de cultivos tradicionales², funcionarios municipales

1. El conocimiento de los actores involucrados en estos procesos proviene del trabajo previo en la Quebrada de Humahuaca a partir de dos tesis de doctorado dedicadas a las transformaciones en la producción agraria local y aquellas vinculadas con la presencia del turismo en la zona (Arzeno, 2008; Troncoso, 2012). A partir de ellas se ha iniciado una línea de indagación en torno a los vínculos entre producción agraria y turismo en la zona (antecedentes de esta indagación pueden encontrarse en Arzeno y Troncoso, 2012; Troncoso y Arzeno, 2017).

2. Entre ellas, en particular, Cauqueva (Cooperativa Agropecuaria y Artesanal Unión Quebrada y Valles) y la Red Puna que han experimentado un crecimiento importante en relación con la producción y comercialización de productos tradicionales. 
y nacionales (especialmente aquellos que trabajan en áreas vinculadas con el estímulo a la producción local y el turismo) ${ }^{3}$, miembros de la Asociación de Turismo de la Quebrada ${ }^{4}$, empresarios que utilizan los productos en sus propuestas gastronómicas en locales en el destino e intermediarios encargados de su comercialización $n^{5}$. Las entrevistas han sido analizadas en torno a ejes de indagación específicos. En el caso de los productores primarios, los empresarios gastronómicos y los intermediarios estos ejes de indagación giraron en torno a desentrañar: a) las estrategias que cada actor diseña en cada caso (producción, comercialización, adquisición o elaboración que involucrara productos tradicionales); b) los vínculos que establecen con otros actores para llevarlos a cabo; c) los elementos que se perciben como dificultades para lograr los objetivos que se habían propuesto. La información obtenida en las entrevistas con funcionarios públicos y representantes de organizaciones gubernamentales se analizó atendiendo a los aspectos relacionados con estrategias, vínculos entre actores y dificultades involucradas en la producción y comercialización de productos o preparaciones locales. Además, para estos casos se indagaron las formas de intervención en torno a los procesos de valorización de productos locales como parte de la política pública.

Asimismo, se realizó una sistematización de la información generada por las organizaciones de productores, los restaurantes y los intermediarios en relación a la transformación y comercialización de productos y preparaciones tradicionales andinas, especialmente aquellas destinadas al consumo turístico. Esto incluye la información consignada en las páginas web de estos actores, los folletos entregados en los locales comerciales y puestos de información turística relacionados con productos y eventos gastronómicos, los menús de los restaurantes locales y los documentos oficiales vinculados con programas de incentivo a la producción local. Esta información se complementa con aquella obtenida de la observación sistemática en los espacios de producción y consumo en el área de estudio (acompañada de registros fotográficos $)^{6}$. Esta información secundaria ha sido analizada buscando complementar la información obtenida mediante las entrevistas.

\section{ANÁLISIS Y RESULTADOS}

\subsection{Procesos recientes de revalorización de la producción agraria tradicional en Quebrada de Humahuaca y Puna}

La Quebrada de Humahuaca es un valle semiárido localizado en los Andes jujeños adyacente a la Puna, una zona árida de altura que se extiende al oeste de la provincia. Tanto la

3. Esto incluye las autoridades vinculadas con la Jefatura de Gabinete y con la Dirección de Turismo de la principal localidad turística de la Quebrada (Tilcara) y los responsables del INTA (Instituto Nacional de Tecnología Agropecuaria) con sede en la Quebrada.

4. Esta asociación nuclea a los empresarios vinculados a los servicios de hospedaje y gastronomía de la zona de la Quebrada.

5. Se trata de intermediarios que adquieren productos tradicionales en estas áreas del país para luego comercializarlas en restaurantes de reconocidos chefs en la ciudad de Buenos Aires o en locales propios dedicados a productos exóticos, naturales, saludables, etc. en la misma ciudad.

6. Esto incluye la visita a los predios de producción, las plantas de elaboración y los locales comerciales de los productos tradicionales. También incluye los espacios de consumo, tanto los vinculados con espacios comerciales como aquellos acondicionados para eventos en la vía pública. 
Quebrada como la Puna han sido áreas de producción agrícola y ganadera desarrollada por la población campesino-indígena de origen andino. En particular la actividad ganadera (ovejas, cabras, llamas y vicuñas) tuvo más desarrollo en el área de la Puna, mientras que la Quebrada ha tenido históricamente un perfil más agrícola y a lo largo del siglo XX se ha especializado en la producción hortícola (verduras de hoja, zanahoria, apio, haba, arveja, entre otros) para mercados regionales. Esta producción ocupa el 61 \% de la superficie implantada en la Quebrada, de acuerdo con datos del Censo Nacional Agropecuario de 2008 (último realizado). Para muchos productores los ingresos generados por la actividad agraria no son suficientes y en algunos casos estos ingresos son fluctuantes dependiendo de la demanda. Es por eso que desde la década de 2000, tanto en la Puna como la Quebrada se han hecho esfuerzos por recuperar la producción de cultivos andinos (papas, maíces, amaranto, quinoa) en la medida en que su producción empieza a ser vista, desde algunas organizaciones y organismos públicos, como alternativa económica para estos pequeños productores.

La Quebrada de Humahuaca como destino turístico, por su parte, experimentó un aumento en el número de visitantes desde fines de la década de 1990 con un crecimiento importante en la década posterior. Esto fue acompañado del surgimiento de una oferta de servicios (alojamiento, gastronomía) que había sido prácticamente inexistente en la zona hasta ese momento. Estos emprendimientos fueron desarrollados en su mayoría por migrantes llegados al lugar con la intención de iniciar estos negocios. En la actualidad tanto los turistas como los servicios se concentran especialmente en tres localidades del valle: Tilcara, Purmamarca y Humahuaca (Troncoso, 2012).

En este marco de la recuperación de cultivos locales, la producción local tradicional comenzó a comercializarse exclusivamente como productos frescos y sin mayor grado de procesamiento. Sin embargo, en años recientes, la producción y comercialización de estos productos se orienta al desarrollo de una incipiente agroindustria. A esto se suma la introducción de un cultivo y una industria novedosos: la vid y la producción local de vinos.

En lo que sigue se realiza una breve descripción de las principales producciones y actores involucrados en la recuperación e incremento de la producción de alimentos tradicionales en la Quebrada y Puna, para luego indagar en las (des)articulaciones con la instancia de consumo vinculada al turismo gastronómico. Se hace mención en particular a la recuperación de cultivos locales, la producción de carne de llama y la nueva producción vitivinícola.

\subsubsection{Cultivos locales: comercialización en fresco y pequeñas agroindustrias}

Las primeras estrategias de recuperación de cultivos tradicionales estuvieron marcadas por la actuación de Cauqueva (Cooperativa Agropecuaria y Artesanal Unión Quebrada y Valles), una cooperativa con más de 20 años de funcionamiento en el área tradicional de producción agropecuaria de la Quebrada de Humahuaca. En el presente cuenta con alrededor de 100 socios a lo largo de la Quebrada y en el departamento de Iruya (provincia de Salta). Se trata de pequeños productores, algunos de ellos ubicados en zonas altas donde desarrollan una ganadería y producción agrícola orientados mayormente al autoconsumo, otros son productores hortícolas del fondo del valle, pero que han incorporado (o incrementado) la producción de productos tradicionales (en particular papas y maíces). 
Coordinada desde sus inicios por un ex técnico agropecuario del INTA, se orientó a trabajar primeramente en la producción de hortalizas buscando mejorar las condiciones de comercialización de los productores hortícolas locales.

Desde inicios de la década del 2000, fue profundizando la recuperación de papas y maíces andinos porque, en virtud de la creciente demanda asociada a los procesos descriptos anteriormente, ya se vislumbraban como productos que tenían valor mayor de mercado que las hortalizas. Fue así como progresivamente la cooperativa comenzó a incorporar la producción y comercialización de papas andinas y encaró la comercialización en supermercados de San Salvador de Jujuy y Buenos Aires, entre otros.

Desde 2012, se fue especializando en la elaboración y venta de productos procesados: fideos a base de maíz (combinados con quinoa, espinaca o saborizados) snacks de maíz (palitos de queso), puré de papas andinas deshidratadas y alfajores elaborados con harina de maíz (figura 1).

En los últimos años han ido creando distintos canales de comercialización que también apuntan al consumo responsable, destacando el componente cultural de los productos, así como su alto valor nutritivo y aptitud para personas con celiaquía. Algunos intentos por posicionar estos productos con el público turístico son la apertura del Museo de la Vida Campesina y un local de ventas de sus productos en Tilcara.

Figura 1: Centro de procesamiento de Cauqueva (Maimará) y fideos elaborados por la cooperativa con harina de maíz
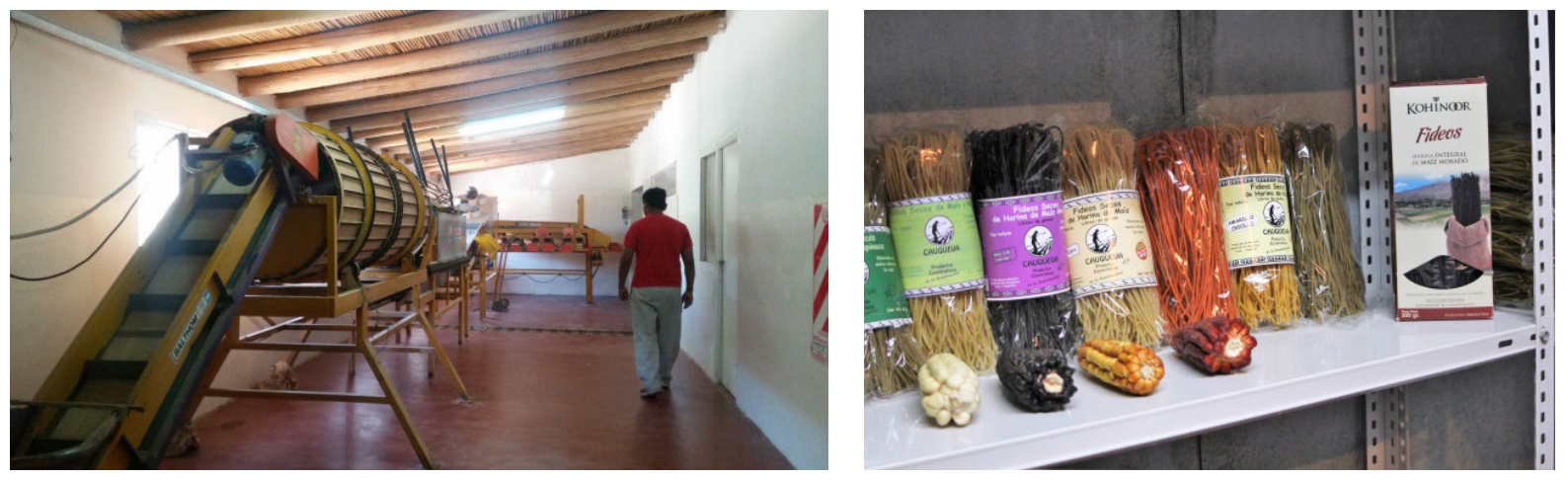

Fotos: Claudia Troncoso y Mariana Arzeno

\subsubsection{La carne de llama: surgimiento y consolidación de nuevas formas de producción y de comercialización}

Los procesos de cambio en torno a la producción y comercialización de la carne de llama (que tiene un uso casi exclusivamente turístico) se han destacado en los últimos años por la trama productiva y comercial que involucra. La mayor simplicidad en cuanto a su manejo (en comparación con otro tipo de ganado como el ovino y el caprino) sumado a la demanda de carne como producto gourmet, condujeron, en años recientes, a un incremento del stock ganadero de un 64\% (entre los censos agropecuarios de 1988 y 2008) y de la producción de carne 
entre los productores familiares (entrevista personal a referente del INTA, 2016; Echenique et al., 2015). El área de producción principal de llama son los departamentos de la Puna y las zonas altas de la Quebrada. Sin embargo, las localidades quebradeñas constituyen puntos de comercialización de dicha producción y sus derivados (distinto tipo de embutidos) en locales gastronómicos y de venta de productos regionales.

Uno de los principales circuitos de producción y comercialización está conformado por redes familiares o de parentesco que involucran a productores campesinos que crían los animales y en general faenan, e intermediarios (mayormente mujeres) que se encargan de la comercialización de la carne en las ferias de las localidades de la Puna, la Quebrada y la capital provincial. Se trata de un circuito con un alto nivel de informalidad, pero que involucra volúmenes considerables de carne y es de relevancia económica en la región (entrevista personal a referente del INTA, 2016; Echenique et al., 2015).

Pero los actores que tienen un rol importante en la promoción del consumo de la carne de llama (además de los lugares gastronómicos y chefs que la incorporan en sus menús) son algunas organizaciones que vienen trabajando y contribuyendo al aumento de la producción local. La Red Puna constituye un ejemplo interesante en este sentido.

Se trata de una organización de segundo grado que nuclea a un conjunto de organizaciones y comunidades aborígenes de la Puna y la Quebrada, que se ha abocado a la recuperación de los alimentos locales, no sólo como estrategia de generación de ingresos en un contexto de fuerte demanda de esos productos, sino también como parte de reivindicaciones políticas (por ejemplo, con relación al problema del acceso legal a la tierra o el logro de la soberanía alimentaria). Como su ámbito de trabajo fue fundamentalmente el área de la Puna y zonas altas de la Quebrada, se ha orientado centralmente a la recuperación de la ganadería (de llamas y ovinos) y más recientemente a la producción de alimentos procesados a partir de la carne de llama. Se trata en este caso de una estrategia que busca articular directamente con el turismo gastronómico, aunque apelando a valores arraigados en demandas políticas de la población campesina.

Se destaca el trabajo de esta organización en la generación de una "agroindustria de la carne de llama", desarrollando una línea de productos que incluyen, además de la carne fresca, derivados como: fiambres, hamburguesas y medallones de carne de llama con quinoa que se venden congelados. Se los promociona como productos sanos y "de la lucha campesina indígena por la soberanía alimentaria" que se "destina al consumo local y popular" con el fin de "enriquecer la cadena de valor y generar nuevas alternativas para las familias de nuestras comunidades" (figura 2). El componente cultural y político de los productos (que en este caso se suma además a las cualidades nutritivas por su forma de producción) constituyen un "valor agregado" que busca despertar el interés de cierto tipo de consumidor responsable. 
Figura 2: Folleto de difusión de la producción de la Red Puna, 2017
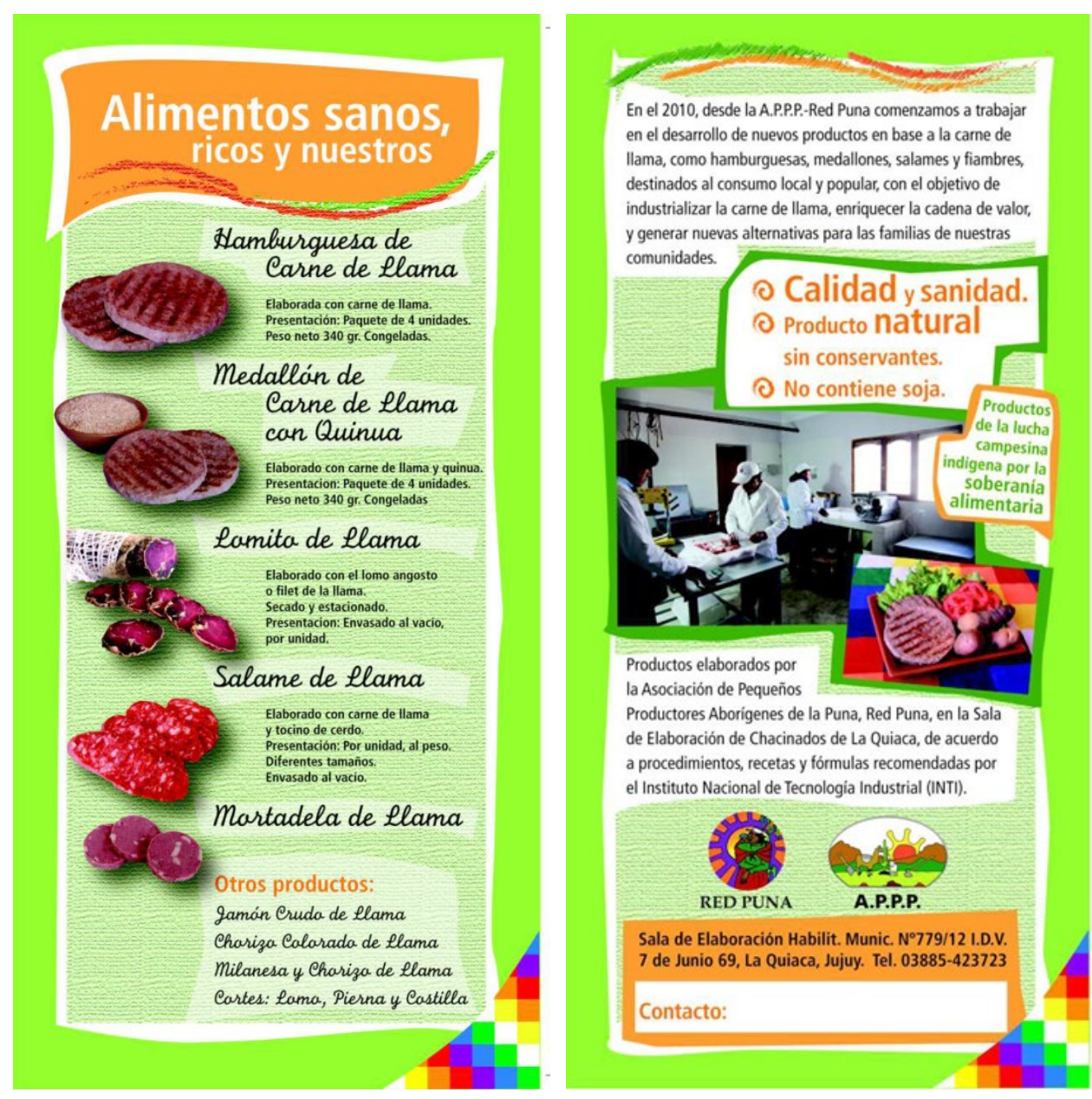

Fuente: Red Puna, Alimentos sanos, ricos y nuestros. Chacinados y embutidos de llama

\subsubsection{Bodegas y producción vitivinícola: un nuevo producto de la mano de nuevos productores}

Si bien el cultivo de vid ha estado presente en la historia productiva de la Quebrada, en la actualidad adquiere la forma de una producción exclusiva que se sintetiza en la figura de la bodega boutique y los vinos de diseño ${ }^{7}$. En la actualidad hay varias bodegas en el valle (ocupando una superficie de 22 hectáreas) $^{8}$. Esta producción se orienta a ser parte de la experiencia turística en la Quebrada: por un lado, algunas de las bodegas ofrecen visitas a sus establecimientos (donde pueden además adquirirse los productos) (figura 3) y, por otro, sus vinos se comercializan en locales y establecimientos turísticos de la Quebrada.

La producción vitivinícola quebradeña recurre a todas las estrategias de diferenciación de productos ya clásicas del vino, en esta ocasión articuladas en torno a las características del lugar en cuestión. Así, la etiqueta del vino Punta Corral de la bodega Dupont afirma: "Punta Corral es un vino de cuerpo notable, producto de la altura y un terruño muy rico en minerales

7. Tal como acontece en otras provincias argentinas, entre ellas Mendoza y Salta.

8. Entre ellas se encuentran: Amanecer andino, Chalala, El Milagro, Dupont, El Perchel, Tukma y Ayni. 
regado con el agua subterránea más pura de nuestro viñedo de Maimará, a 2500 metros de altura sobre el nivel del mar". Asimismo, menciona que la bodega "se encuentra en la Quebrada de Humahuaca Patrimonio Natural y Cultural de la Humanidad -UNESCO".

La importancia de la singularidad se expresa en la manera en que se promociona otro de los vinos quebradeños de la bodega Tukma. El nombre de su sauvignon blanc (Altura 2600) hace referencia a la altura sobre el nivel del mar de los viñedos que le dan origen; ellos son promocionados afirmando que "a esta altura nuestros viñedos son los más altos del mundo para este varietal" (página web Bodega Tukma), dando cuenta de la excepcionalidad que se intenta destacar para este producto ${ }^{9}$.

Cabe mencionar además que esta experiencia de introducción de la vitivinicultura es encarada, en general, por emprendedores provenientes de otros lugares del país. Esto marca una diferencia con la producción de alimentos andinos, donde tiene un rol protagónico las organizaciones y pequeños productores locales.

Figura 3: Viñedos y visitas guiadas (Maimará). 2016

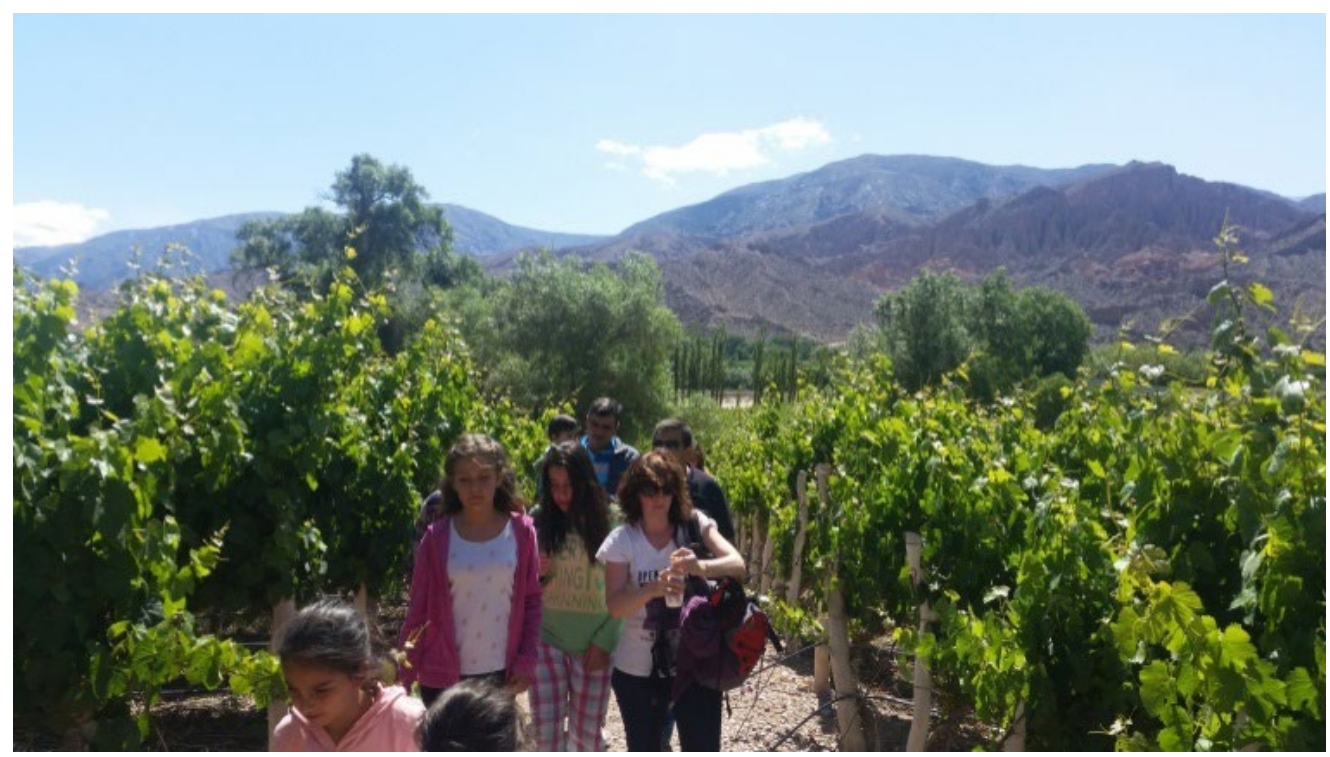

Foto: Claudia Troncoso

\subsubsection{Revalorización de alimentos tradicionales: un camino sinuoso}

Si atendemos a los aspectos productivos, la revalorización de la producción agraria tradicional dio lugar a un incremento de su producción (en algunas producciones más que en otras) y a una incipiente agroindustria a través de la intervención y articulación de diversos actores. También estuvo marcada por la presencia de producciones novedosas en el contexto quebradeño como la vitivinicultura.

9. La referencia a la altura sobre el nivel del mar a la cual se produce el cultivo como elemento distintivo es tradicional de los vinos producidos en Salta. Los vinos de la Quebrada buscan diferenciarse porque se obtienen a una altura todavía más elevada que aquellos de la provincia vecina. 
Sin embargo, a diferencia de la vitivinicultura que es movilizada por emprendedores individuales que se orientan a un mercado reducido de alta rentabilidad y generalmente externo a la Quebrada, los intentos de la población local y algunas organizaciones por recuperar e instalar los productos tradicionales han experimentado (y experimentan) dificultades. Por un lado, aquellas vinculadas con la producción en mayor escala (que sería necesaria para lograr un abastecimiento continuo a los locales gastronómicos) ya que ella requiere de la recuperación y mejora de infraestructura de riego, así como un trabajo importante en materia de manejo de los cultivos (por ejemplo, por el problema de sanidad de la papa andina) y de realización de tareas de cosecha específicas (generando tecnología apropiada al lugar, los cultivos y los productores). En este punto viene actuando el INTA a partir del desarrollo de tecnología para el tratamiento postcosecha de la quinoa, dado que se lo ve como uno de los principales condicionamientos para un incremento de la producción. ${ }^{10}$ Por otro lado, se encuentran las dificultades vinculadas con la menor disponibilidad de mano de obra entre los productores como consecuencia de su inserción en el mercado laboral local. En efecto, algunas actividades urbanas (generalmente en el sector servicios) u otras como la minería (de reciente reactivación a nivel provincial) constituyen atractivas opciones laborales alternativas a la horticultura y la producción agro-ganadera de subsistencia. Esto incluye un proceso de desvinculación de las generaciones más jóvenes de la actividad agraria, que se traduce en el abandono de la tierra y la migración. ${ }^{11}$

Estos aspectos dificultan que la incipiente reactivación productiva se articule con la creciente demanda gastronómica local. De ahí que las estrategias de las organizaciones se orienten cada vez más hacia el procesamiento industrial que les permite agregar valor en sí mismo al producto, pero además captar mayores ingresos al adaptarlo al consumo de los turistas (y en general de los consumidores urbanos). Este será el público a quien se dirigen estos productos que se promocionan en relación con sus atributos nutricionales, geográficos, culturales, políticos, etc.

\subsection{La demanda de productos tradicionales: restaurantes, turistas y estetización de los alimentos andinos}

Los productos y preparaciones culinarias andinas definen una oferta gastronómica nucleada en un conjunto de emprendimientos que se han instalado en la Quebrada desde comienzos de la década de 2000. Estos emprendimientos han apuntado, en su gran mayoría, a atraer a un turista de alto poder adquisitivo con servicios "a medida" y productos exclusivos buscando combinar lo autóctono con estilos, técnicas y estéticas que acompañan

10. Más allá de estos esfuerzos, la superficie con quinoa sigue siendo minoritaria: ascendía en 2015 a 11 ha en la Quebrada y a 46 ha en la Puna (Ministerio de Agroindustria de la Nación, 2016).

11. Por ejemplo, un referente de una organización local plantea que incluso en la principal zona hortícola, los hijos de los productores locales venden las tierras a productores provenientes de Bolivia que buscan insertarse en la horticultura local. Un referente del INTA hizo referencia a una situación que aún persiste: "en el año 2004, cuando se reactivó la minería, exportaciones minerales, inmediatamente, se empezaron a poblar las rutas locales, la gente que se iba a los salares, borateras, minas, y las comunidades quedaron con mujeres, jovencitas, ancianos, y hoy lo que se está viendo es comunidades realmente despobladas con población envejecida" (entrevista personal con referente del INTA, 2016). 
transformaciones generales en la gastronomía (como, por ejemplo, la cocina fusión). Surgen así platos como la llama al Malbec y el risotto de quinoa (figura 4) y otros como quesito de cabra tibio en hojaldre, mousse de cayote sobre húmedo de chocolate o yacón flambeado al vino tinto, etc. Un reconocido chef, pionero en estas innovaciones, señalaba en los inicios del proceso de gourmetización de la producción y comidas locales que "...fuimos mezclando nuestros sabores hasta lograr un plato más afín al turista, tanto en nombre como en presentación" (Carta Abierta Jujuy, 2004: 7).

Figura 4: Menú de restaurante (Purmamarca). 2016

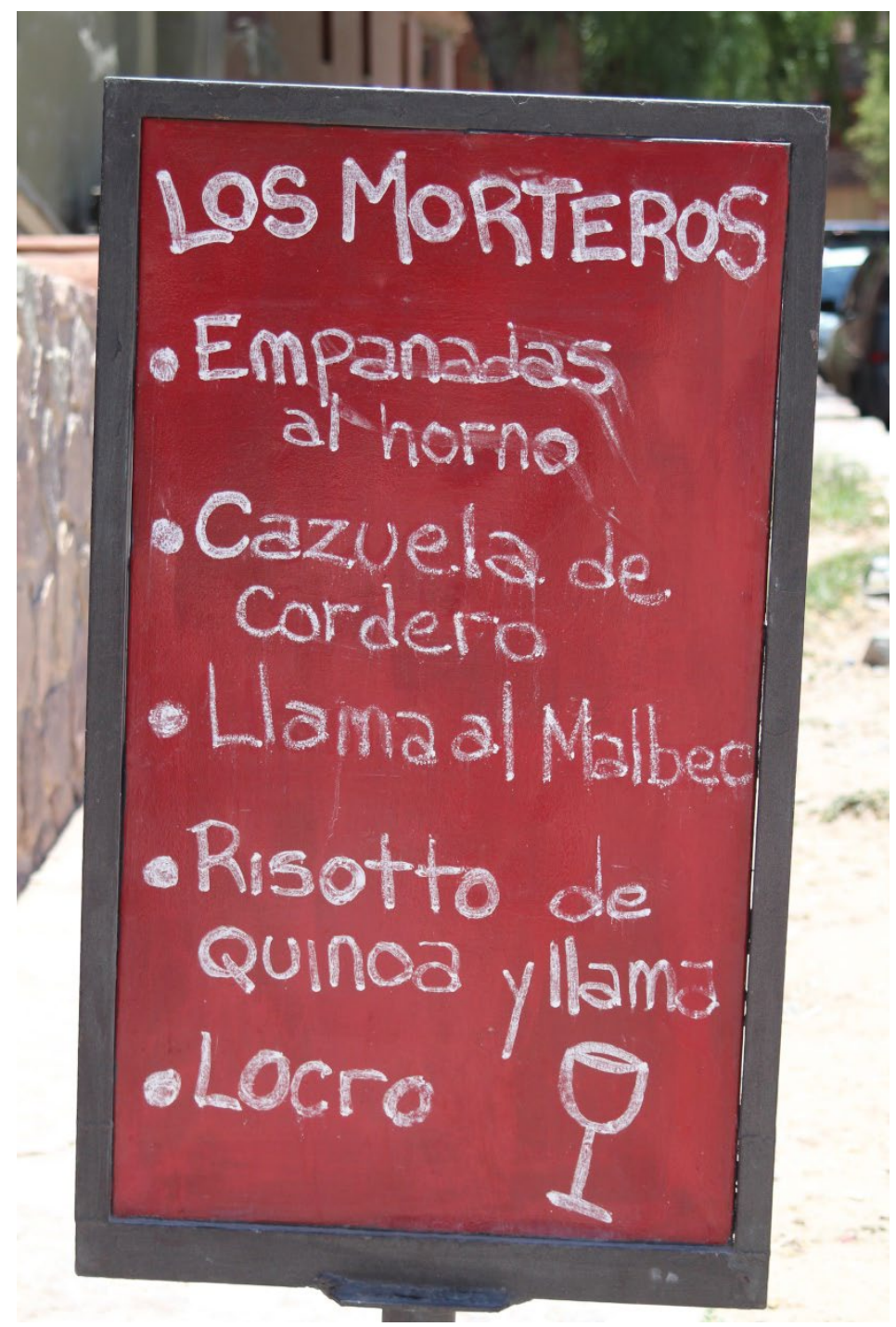

Foto: Mariana Arzeno

El interés por productos y preparaciones locales también ha dado lugar a iniciativas de formación gastronómica. En 2009 se creó en la localidad quebradeña de Tumbaya la Tecnicatura Superior en Comida Regional y Cultura Alimentaria. Esta institución considera "el sector gastronómico como una parte fundamental de la cultura local" y señala que "su 
tratamiento profesional ... constituye, asimismo, un elemento constitutivo del atractivo turístico de la región, y aún de la provincia en su conjunto" (INTA, video institucional, 28/1/2016).

Además la propuesta de formación es legitimada en tanto guardiana del patrimonio, al plantear que la carrera "se fundamenta en la necesidad de rescatar, revalorizar y preservar costumbres tradicionales en relación con el ámbito culinario autóctono, principalmente en una región de tan rica herencia patrimonial, como lo es la Quebrada de Humahuaca, declarada PATRIMONIO NATURAL Y CULTURAL DE LA HUMANIDAD" (ibid).

Los procesos hasta aquí señalados dan indicios de una revalorización de cultivos y preparaciones gastronómicas en la Quebrada. Sin embargo, en la práctica, la demanda de estos productos por parte del sector gastronómico se satisface sólo parcialmente con la producción de la zona: "Tilcara produce un montón de cosas y prácticamente no vende nada acá de lo que produce" (entrevista personal a funcionario municipal, 2016) ${ }^{12}$.

Los mercados de las localidades quebradeñas son los lugares de abastecimiento más frecuente para quienes tienen restaurantes. Allí se obtienen los productos andinos tradicionales, la carne de llama, el queso de cabra y las hortalizas (de producción local o provenientes del sur de la provincia de Jujuy) (entrevista personal con empresaria gastronómica y con funcionario municipal, Tilcara, 2016). Sin embargo, en lo que respecta a los productos andinos, con excepción de la carne de llama, los mayores volúmenes que se comercializan provienen de Bolivia (especialmente la papa y la quinoa). En menor medida estos productos se compran a productores quebradeños dados sus elevados costos; como afirma una empresaria gastronómica "la quinoa de Bolivia está a mitad de precio que la local" (entrevista personal, 2016).

Asimismo, quienes demandan estos productos (hoteleros y dueños de restaurantes) señalan cierto riesgo en tratar con productores locales debido a la discontinuidad en su provisión. En palabras del responsable de turismo de la Municipalidad de Tilcara: "Hay un consumo [de la producción local], lo que pasa es que... siempre el reclamo es que a ellos les parece que la producción local es muy inconstante, no la pueden contar; 'cómo la voy a poner en el menú si hoy está, mañana no está'” (entrevista personal, 2016). Esta discontinuidad en la provisión de productos se vincula con las dificultades de su producción y comercialización mencionadas anteriormente.

No obstante, desde el sector privado vinculado al turismo se suman iniciativas promoviendo la gastronomía local. A partir de 2017 algunos restaurantes de Tilcara crearon el evento gastronómico titulado "Picotear. Cocinando entre cerros" que se define como una "Feria itinerante de sabores y cocineros de Tilcara" (página de Facebook del evento). Las ediciones mensuales suelen estar tematizadas en torno a algún producto local particular (papas andinas, queso de cabra, picantes, etc.).

12. Aunque la principal actividad agropecuaria del departamento es la horticultura ella se comercializa fuera de la Quebrada. 
Otras iniciativas han venido de la mano de algunas organizaciones de productores que han establecido locales propios en Tilcara ${ }^{13}$. En efecto, como habíamos mencionado, Cauqueva comercializa de manera directa sus productos frescos (papines) y elaborados (fideos, palitos de maíz, etc.) en un local comercial desde $2016^{14}$. Los clientes están compuestos por residentes en la localidad llegados de otras ciudades del país (profesionales, artesanos) y algunos turistas. En la misma localidad la Red Puna tiene, desde 2013, un local en el que ofrece al público tejidos elaborados con lana de llama y oveja, a los que se suman diferentes chacinados de carne de llama. Los clientes se componen principalmente por turistas (Figura 5).

Figura 5: Local de la Red Puna (Tilcara). 2016

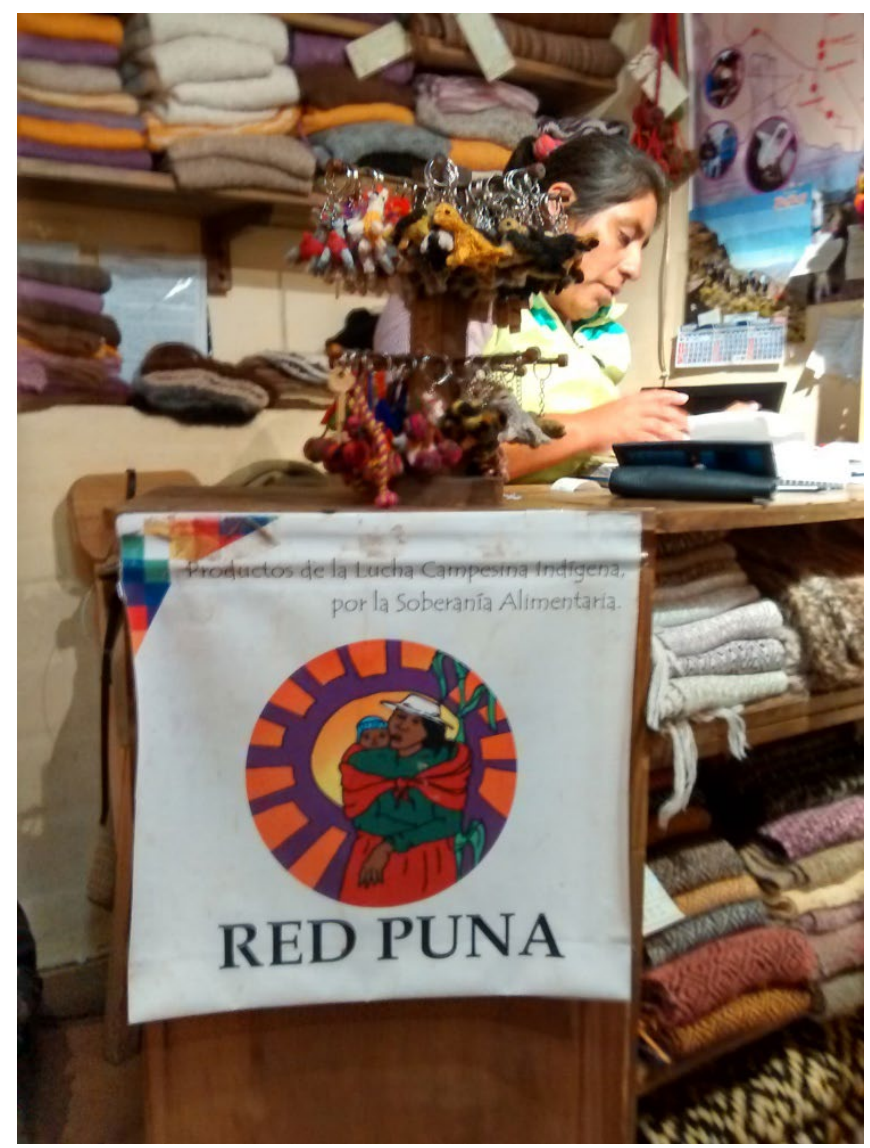

Foto: Mariana Arzeno

Estas iniciativas que ofrecen diversos productos y servicios asociados a los alimentos locales redefinen el destino turístico a partir de las nuevas formas de consumo. Asistimos a

13. Además de la comercialización de productos en el mismo destino turístico, las organizaciones de productores también participan de redes de comercialización vía intermediarios que hacen posible la venta de productos quebradeños en varias localidades argentinas.

14. También comercializa sus productos en Buenos Aires, Córdoba, Mendoza, San Miguel de Tucumán y San Salvador de Jujuy. Además participa en ferias gastronómicas en la ciudad de Buenos Aires (entre ellas Masticar, Buenos Aires Market y Caminos y sabores). Algunos restaurantes exclusivos de la capital argentina también demandan eventualmente sus productos. 
propuestas "gourmetizadas" de productos y platos tradicionales que recuperan el interés en lo local pero que también apuntan a un consumo sofisticado. Esto está asociado a un nuevo consumidor (generalmente de clase media) que busca diferenciarse del consumidor estándar al exhibir cierto capital cultural (que le permite apreciar estos productos). Y aquí cabe señalar la convergencia en estas formas de consumo que reúne a consumidores con intereses similares: los turistas y ciertos sectores de los residentes, justamente aquellos llegados de otros lugares del país. Asimismo, estas nuevas propuestas gastronómicas también redefinen el uso del espacio público en eventos que incluyen disfrutar de música y otras actividades culturales, etc. Se trata de una tendencia de llevar adelante el acto de comer al menos para ciertos sectores que ha marcado los espacios urbanos, especialmente de las grandes ciudades, pero que se replica en estas pequeñas localidades turísticas.

\subsection{La política pública y los incentivos a la producción y consumo de productos tradicionales}

Conforme la producción y consumo de productos y alimentos tradicionales comenzó a cobrar peso en la zona, desde el ámbito público se definieron líneas de acción para incentivar y mejorar la producción y su comercialización. Esto implicó la intervención y el accionar de diversas entidades estatales que buscaron dar respuesta a los problemas ya mencionados que enfrentan la producción y comercialización de este tipo de productos.

En particular cabe destacar desde el ámbito nacional las acciones orientadas a brindar asesoramiento técnico de varios organismos. Entre ellos el INTA, a través de su Instituto para la Agricultura Familiar (IPAF) con sede en la Quebrada, cuenta con varias líneas de investigación y desarrollo de tecnología apropiada para los cultivos locales (quinoa, kiwicha, papas andinas) (entrevista personal a referente del INTA, 2016). También el Instituto Nacional de Tecnología Industrial (INTI) prestó asesoramiento en la producción agroindustrial en base a la carne de llama (Red Puna, Alimentos sanos, ricos y nuestros). A su vez, el Ministerio de Desarrollo Social de la Nación ha financiado la renovación de maquinaria en la planta procesadora de Cauqueva (Video Institucional del Ministerio de Desarrollo Social de la Nación).

En el ámbito del gobierno local, por su parte, se están discutiendo acciones orientadas específicamente a conectar a productores y empresarios y superar aquella desarticulación que mencionamos anteriormente. Esto se vio facilitado a partir de la participación en la gestión municipal de funcionarios que provienen del ámbito cooperativo o privado vinculado a la producción agraria y al turismo (se trata, a su vez, de migrantes llegados en las últimas décadas a la Quebrada).

Un funcionario municipal de Tilcara (miembro de la cooperativa Cauqueva) precisa las ideas e iniciativas contempladas para la nueva gestión que se inició en 2015:

"Lo que queremos es que se integren todos en cadenas". [...] "Nosotros lo que estamos haciendo ahora es un relevamiento de qué compran los restaurantes y hoteles. [...] Decir bueno esto es lo que ellos compran; nos interesa, no nos interesa. Si nos interesa, generar una mesa tripartita donde el Municipio actúe de árbitro para evitar excesos pero que haya una negociación directa 
Turismo, gastronomía y producción agraria en la provincia de Jujuy (Argentina): actores, dinámicas y transformaciones asociadas a la valorización de productos tradicionales

productor- empresario. Y perfectamente Cauqueva podría sentarse en esa mesa" (entrevista personal, 2016)

Este plan incluye la vinculación productor local-empresario turístico para un conjunto amplio de producciones locales, más allá de los productos tradicionales (suma, por ejemplo, carnes y lácteos). También se busca establecer el mercado como lugar de encuentro entre productor y consumidor a través de la creación de un puesto de venta municipal mayorista donde converjan productores y empresarios hoteleros y gastronómicos. Además, se propone recurrir a las estrategias de certificación de alimentos difundidas en la actualidad procurando "jerarquizar" productos y preparaciones locales. De acuerdo con un funcionario municipal que a su vez es empresario turístico (miembro de la Asociación de Turismo de Quebrada y Puna):

"Lo que estamos laburando [trabajando] con la Asociación de Turismo primero, y después hacia todos, es negociar una producción por parte de los productores que sea agroecológica. Ir caminando hacia la agroecología y un compromiso de compra por parte de los emprendedores turísticos. El INTA y la Muni certificarían esa producción y certificarían a los negocios que compren esos productos" (entrevista personal, 2016).

Las dimensiones estéticas no están ausentes en las iniciativas vinculadas con la promoción de la gastronomía local como atractivo turístico. Aquí los restaurantes y sus propuestas sofisticadas son el modelo a seguir aun para las opciones más populares que se ofrecen en la Quebrada. Un funcionario/empresario del área de turismo expresa la intención de hacer más atractivas las opciones gastronómicas elaboradas por habitantes tradicionales que no han sido expresamente pensadas para el turista sino para otros lugareños. Plantea la necesidad de "darles una mano" a las cocineras populares para que incorporen "un toque gourmet" a sus comidas y para que mejoren la ambientación de los locales gastronómicos ("lookear un poco su cocinita o su puestito", entrevista personal, 2016). La estetización propuesta para estas otras opciones gastronómicas está en concordancia con las múltiples dimensiones que están en juego en la actual apreciación turística de la comida que incluye aspectos como la apariencia y la ambientación. A partir de esta propuesta, proveniente de un actor que detenta cierta mirada foránea acerca del lugar (y en cierta medida comparte la apreciación turística sobre lo local), cabe preguntarse si no se trata de hacer extensivos a otros sectores sociales aquellos intereses, gustos o predisposiciones estéticas naturalizándolas y asumiendo su universalidad (Duncan y Duncan, 2001). Estas ideas también hablan de un comportamiento o accionar esperable que deberían tener ciertos actores locales en función de la demanda turística actual (Edensor, 2006).

Además de favorecer la comercialización local de la producción y sugerir adaptaciones gastronómicas, desde el municipio de la localidad de Tilcara existen otros proyectos orientados a destacar los productos y la gastronomía local. Uno de ellos es el Festival Gastronómico Andino de Tilcara (figura 6) realizado anualmente desde 2016 organizado con el objetivo de "revalorizar la cocina andina" (entrevista personal con funcionario municipal del área de turismo, 2016). El programa de este evento incluye, entre otras cosas, clases magistrales de cocina a cargo de docentes y alumnos de la Tecnicatura Superior en Comida Regional y Cultura Alimentaria. Asimismo, varios restaurantes de la localidad elaboran menús del día incluyendo productos locales. Estos establecimientos suelen ocupar el espacio público. El evento suma la 
degustación de vinos elaborados por los recientes emprendimientos de la zona y se completa con una feria campesina compuesta por puestos de ventas de productos, charlas vinculadas a la temática gastronómica y otras actividades culturales. Todo esto abona lo señalado en el punto precedente respecto de las tendencias actuales de llevar el acto de comer al espacio público que marcan el consumo gastronómico.

Figura 6: Poster del primer Festival Gastronómico Andino

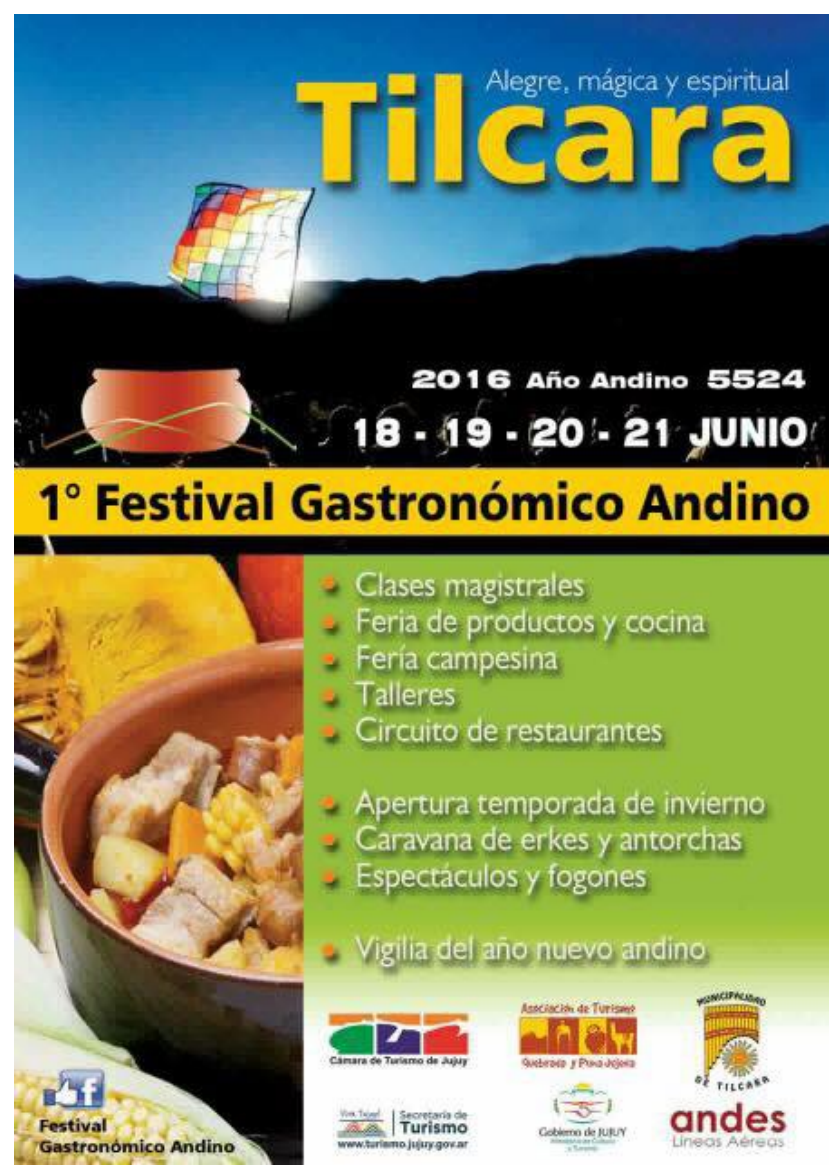

Fuente: Página Facebook Festival Gastronómico Andino

La apreciación positiva sobre los productos tradicionales y la importancia que revisten en términos del consumo turístico ha llevado a presentar numerosas iniciativas de gestión también a nivel provincial. A inicios de 2016 desde el gobierno provincial (Ministerio de Cultura y Turismo y Ministerio de Desarrollo Económico y Producción) se ha anunciado el proyecto de crear un circuito turístico "Ruta de la Pachamama" que, con una fuerte presencia de la gastronomía y la vitivinicultura buscaría nuclear todas las regiones de la provincia. Así lo expresó el ministro de Cultura y Turismo provincial: "el desarrollo del turismo tiene tres patas: lo paisajístico, lo cultural y lo gastronómico, y el hecho de que tengamos esta diversidad cultural nos permite pensar en la posibilidad de desarrollar productos turísticos gastronómicos de alta calidad a partir de desarrollar rutas específicas" (El Federal, 17/2/2016). Si bien a nivel local los actores vinculados al sector público y al sector privado afirman que este proyecto aún no se ha impulsado de manera concreta, en 2017 el gobierno provincial ha insistido nuevamente 
con este tipo de iniciativas priorizando la producción vitivinícola que se está desarrollando en la zona ${ }^{15}$.

Saber experto, poder político y empresariado turístico conjugan una serie de saberes, acciones e intervenciones que convocan actores de diferentes instituciones, niveles de gobierno y ámbitos de injerencia. Todos ellos también colaboran en la definición de las redes de relaciones que caracterizan en particular a la Quebrada como lugar turístico y gastronómico.

\section{CONCLUSIONES}

Este trabajo buscó indagar cómo se ha transformado el panorama productivo y turístico de ciertas áreas de la provincia de Jujuy en vinculación con la recuperación de alimentos tradicionales. Específicamente abordó esta cuestión analizando quiénes son los actores que participan (y cómo lo hacen), cuáles son las relaciones que existen entre ellos y cómo esto configura a estas áreas jujeñas como un lugar de producción-consumo en relación con tendencias actuales más amplias. Para ello, se procuró retomar discusiones de la Geografía para el análisis de la complejidad de actores, relaciones, acciones que permiten comprender los cambios que definieron estos ámbitos. A partir de este caso y con este tipo de análisis se intentó aportar elementos a la discusión acerca de la relación entre turismo, producción agraria y desarrollo.

La investigación llevada adelante muestra que, en el caso de esta región argentina, la recuperación de los alimentos tradicionales es un proceso impulsado por ciertos actores (originariamente técnicos de ONGs o del estado) que pasaron a formar parte de organizaciones de base, o bien actores foráneos interesados en desarrollar un emprendimiento comercial. Ellos han sido clave para situar estos productos en el nuevo mapa mundial de alimentos y preparaciones locales, tejiendo distintas redes dentro y fuera del lugar con el fin de posicionar sus productos en un mercado "de nicho".

Asimismo se trata de actores que no habían tenido participación en las formas tradicionales de la producción agraria local pero se suman conociendo con detalle los aspectos de la demanda de estos productos (este es el caso de Cauqueva impulsada y asesorada por profesionales que conocen las demandas del mercado actual -tal vez por formar parte del sector de la sociedad que demanda estos productos). La presencia de este tipo de actor da cuenta de que no existe un perfil homogéneo de la sociedad local en los destinos turísticos ni una historia internalizada que define características únicas y esenciales del lugar: buena parte de las iniciativas de rescate de productos ha involucrado tanto productores locales como actores de fuera del lugar. Asimismo, cuestiona la idea difundida por el marketing turístico que reconoce exclusivamente a los productores tradicionales como artífices de este rescate y puesta en producción de cultivos locales (aquellos actores migrantes han tenido un rol central a la hora de definir el rumbo productivo de Quebrada y Puna).

En efecto, tanto los empresarios turísticos y gastronómicos como algunos residentes, funcionarios y los propios turistas (pertenecientes a la clase media urbana, con cierto capital económico y cultural - Goodman, 2010) son quienes se alinean en torno a determinados

15. Esto incluye el otorgamiento de créditos para estimular esta producción a nivel local (Jujuy Online, 2017). 
gustos e ideas estéticas acerca de cómo se deben ver, disfrutar, consumir y comercializar los productos agrarios andinos, cómo el lugar debe ser para ser consumido y eventualmente, para alcanzar el desarrollo vía el consumo turístico. Esto se hace evidente en los intentos por introducir aspectos estéticos en las formas de presentar productos y preparaciones tradicionales en función de nuevos intereses gastronómicos.

Esta discusión aporta elementos para tratar la cuestión de la identidad y el sentido de lugar que está muy presente especialmente en ámbitos que fueron definidos por ciertos sectores sociales e institucionales como locus de una especificidad valor(iz)ada por sus cualidades únicas frente a la tendencia global "homogeneizante" y también muy presentes en las propuestas de desarrollo para esos lugares. Por ejemplo, la identidad de la Quebrada (e indirectamente la Puna) como lugar único (aquello que la convierte en objeto de valorización turística) es producto de un proceso en el que ciertos actores, relaciones e intercambios tuvieron y tienen un rol central. Son estos actores los que construyen en definitiva un lugar turístico pensado por (y en cierta forma para) el consumo de sectores sociales específicos.

Todo esto permite comprender a la Quebrada y la Puna jujeña como un área que articula tendencias globales vinculadas al consumo y a la producción (que incluyen tanto estrategias productivas como ideas acerca de qué y cómo consumir) con procesos vinculados a la producción tradicional que han caracterizado la historia de esta zona. Pero también lo señalado invita a tomar en cuenta la conformación del lugar como destino turístico (y de migración de algunos turistas); su condición de espacio de actuación de la política pública a diferentes niveles (nacional, provincial y local); su historia marcada por la conformación de colectivos vinculados a intereses productivos, sociales y políticos; su condición altamente visible de Patrimonio Mundial; y su situación de locación apetecible para inversiones de todo tipo (desde turísticas o gastronómicas hasta productivas como las vinculadas a la vitivinicultura). Estas formas de pensar un destino turístico son habilitadas a partir de la concepción de lugar como red de relaciones que se concretan geográficamente de manera diferencial.

El análisis realizado para el caso jujeño permite también considerar nuevas aproximaciones al tratamiento de la relación turismo, producción agraria y desarrollo que se alejen de miradas habituales, propias del marketing turístico. En buena medida lo señalado parece cuestionar aquellas perspectivas que conciben a la intervención como un acto catalizador que pone en contacto dos partes para lograr un efecto buscado y que se expresa en la fórmula: producción tradicional + intervención + interés desde el consumo en esos productos = situación win win expresada en desarrollo local + satisfacción del consumidor. La promoción y expansión del turismo, y específicamente del turismo gastronómico, no significa una traducción simultánea en un "desarrollo" que tenga como protagonistas al sector mayoritario de los productores y población local. 


\section{REFERENCIAS BIBLIOGRÁFICAS}

Amaya-Corchuelo, S., Froehlich, J. y Aguilar Criado, E. (2019). Singularidades en venta. Uso de valores culturales y construcción de la distintividad en los casos de jamón ibérico en España y de la carne de la Pampa en Brasil. AGER. Revista de Estudios sobre Despoblación y Desarrollo Rural, 26, 35-66.

Arzeno, M. (2008). Pequeños productores campesinos y transformaciones socioespaciales. El cambio agrario en la Quebrada de Humahuaca (Jujuy). Buenos Aires: Tesis de Doctorado, Facultad de Filosofía y Letras, Universidad de Buenos Aires. Disponible en: http://repositorio.filo.uba.ar/handle/filodigital/1740

Arzeno, M. y Troncoso, C. (2012). Alimentos tradicionales andinos, turismo y lugar: definiendo la nueva geografía de la Quebrada de Humahuaca. Revista de Geografía Norte Grande, 52, 71-90.

Barros, C. (2000). Reflexiones sobre la relación entre lugar y comunidad. Documents d'Anàlisi Geogràfica 37, 81-94.

Bessière, J., Mognard, É. y Tibère, L. (2016). Tourisme et expérience alimentaire Le cas du SudOuest Français. Téoros, 35 (2).

Cohen, E. y Avieli, N. (2004). Food in tourism. Attraction and Impediment. Annals of Tourism Research, 31 (4), 755-778.

Csergo, J. (2016). Tourisme et gastronomie Quelques réflexions sur les conditions d'émergence d'un phénomène culturel. Téoros, 35 (2).

Dixit, S. (Ed.) (2019) The Routledge handbook of gastronomic tourism. London: Routledge.

Duncan, J. y Duncan, N. (2001). The aestheticization of the politics of landscape preservation. Annals of the Association of American Geographers, 91 (2), 387-409.

Echenique, M., Chavez, M., Vittar, M., Longoni, A. (2015). La producción y comercialización de carne de la agricultura familiar en la Puna Jujeña: análisis de sistemas ganaderos, tramas comerciales y marcos normativos para el diseño de estrategias de desarrollo. Posta de Hornillos, Jujuy: Ediciones INTA.

Edensor, T. (2006). Performing rurality. En P. Cloke, T. Marsden y P. Mooney (Eds.) Handbook of rural studies (pp. 485-495). London: Sage.

Goodman, D. (2010). Place and Space in Alternative Food Networks: Connecting Production and Consumption. En M.K. Goodman, D. Goodman \& M. Redclift (Eds.) Consuming Space. Placing Consumption in Perspective, (pp. 189-211). Farnham, England: Ashgate.

Hall, C. M., Sharples, L., Mitchell, R., Macionis, N. y Cambourne, B. (Coord.) (2013) Food Tourism Around the World Development, management and markets. Oxford: Butterworth-Heinemann.

Hernández-Mogollón, J., Di-Clemente, E. y López-Guzmán, T. (2015). El turismo gastronómico como experiencia cultural. El caso práctico de la ciudad de Cáceres (España). Boletín de la Asociación de Geógrafos Españoles, 68, 407-427.

López-Guzmán, T. y Jesús, M. (2011). Turismo, cultura y gastronomía. Una aproximación a las rutas culinarias. Tourism \& Management Studies, 1, 917-922.

Massey, D. (2007). Geometrías del poder y la conceptualización del espacio. Conferencia dictada en la Universidad Central de Venezuela, Caracas, 17 de setiembre, 2007.

Massey, D. (2012). Un sentido global del lugar. En A. Albet y N. Benach Doreen Massey. Un sentido global del lugar (pp. 112-129). Barcelona: Icaria. 
Matta, R. (2012). El patrimonio culinario peruano ante UNESCO: algunas reflexiones de gastro-política. desiguALdades.net Working Paper Series, 28.

Millán Vázquez de la Torre, G., Morales Fernández, E.y Pérez Naranjo, L. (2014). Turismo gastronómico, denominaciones de origen y desarrollo rural en Andalucía: situación actual. Boletín de la Asociación de Geógrafos Españoles, 65, 113-137.

Mowforth, M. y Munt, I. (1998). Tourism and sustainability. New tourism in the Third World. Londres: Routledge.

Norrild, J. (Coord.) (2016) Gastronomía y turismo. Destinos con sal y pimienta, Buenos Aires, CIET.

Prat Forga, J. M., y Cànoves Valiente, G. (2012). Costa Brava Culinary Tourism Routes and Relational Dynamics. International Journal of Tourism Sciences, 12(3), 47-68.

Salazar, N. (2006). Antropología del turismo en países en desarrollo: análisis crítico de las culturas, poderes e identidades generados por el turismo. Tabula Rasa, 5, 99-128.

Salazar, N. (2012). Community-based cultural tourism: issues, threats and opportunities. Journal of Sustainable Tourism, 20 (1), 9-22.

Sidali K., Spiller, A. y Schulze, B. (Ed.) (2011) Food, agri-culture and tourism. Linking local gastronomy and rural tourism: interdisciplinary perspectives. London and New York: Springer.

Torres, M. y Momsen, J. (Ed.) (2011) Tourism and agriculture. New geographies of consumption, production and rural restructuring. London: Routledge.

Troncoso, C. y Arzeno, M. (2017). Turismo gastronómico en el noroeste de la Argentina. Experiencias de recuperación de alimentos y preparaciones culinarias locales. Congreso Internacional de Investigación, "Turismo y Buen Vivir", Octubre 26 y 27 de 2017, Universidad Externado de Colombia.

Troncoso, C. (2012). Turismo y patrimonio en la Quebrada de Humahuaca. Lugares, actores y conflictos en la definición de un destino turístico argentino, Pasos Edita $\mathrm{N}^{\circ} 9$. Disponible en: http://www.pasosonline.org/Publicados/pasosoedita/PSEdita9.pdf

\section{Fuentes}

Alimentos Argentinos, Cultivos andinos http://www.alimentosargentinos.gob.ar/Home Alimentos/Cultivos\%20Andinos/22/09/2018.

Bodega Tukma, http://tukma.com/

Carta Abierta Jujuy. Para paladares exigentes, febrero-marzo 2004.

Cauqueva, Video Institucional del Ministerio de Desarrollo Social de Argentina, 22/7/2017. Disponible en: https://es-la.facebook.com/pg/cauqueva/posts/

Complejo Quinua Jujuy, página facebook: Información. Disponible en: https://es-la.facebook. $\mathrm{com} / \mathrm{pg} /$ quinuadejujuy/about/?ref=page internal

El Federal, Presentaron la Ruta de la Pachamama en Jujuy, 17/2/2016, https://www.elfederal. com.ar/presentaron-la-ruta-de-la-pachamama-en-jujuy/

INDEC (2008) Censo Nacional Agropecuario. Disponible en: https://www.indec.gov.ar/nivel4 default.asp?id tema 1=3\&id tema 2=8\&id tema $3=87$

INTA, Videoinstitucional:Tumbaya:una escuela decocinaconmuchaaltura,17/1/2016. Disponible en: http://inta.gob.ar/videos/tumbaya-una-escuela-de-cocina-con-mucha-altura 
Jujuy Online, Anunciaron líneas de créditos para la actividad vitivinícola de la Quebrada, 17/7/2017, https://www.jujuyonlinenoticias.com.ar/jujuy/2017/7/17/anunciaron-linea-creditos-para-actividad-vitivinicola-quebrada-43911.html

Ministerio de Agroindustria de la Nación (2016) Plan de Mejora Competitiva. Complejo quinua de Jujuy.

Ministerio de Desarrollo Económico y Producción de Jujuy (2016) Plan de Implementación Provincial.

Organización Mundial del Turismo (2017). Second Global report on gastronomy tourism. Affiliate Members Report, 16.

Picotear Tilcara, página de Facebook del evento. Disponible en: https://www.facebook.com/ picoteartilcaracocinandoentrecerros/?hc ref=ARTLEYZsDryWeh12dJYG3bKkBI9y9ltNC-g191z4STgkP0wGad8k9 LNh-iwuepN9Xs

Red Puna, Alimentos sanos, ricos y nuestros. Chacinados y embutidos de llama. Disponible en: https://redpuna.jimdo.com/productos-de-la-vida-indigena-campesina/agroindustriade-carne-de-llama/

Tecnicatura Superior en Cocinas Regionales y Cultura Alimentaria Tumbaya, página Facebook: Historia. Disponible en: https://www.facebook.com/pg/tecnicaturadetumbaya/ about/?ref=page internal 